\title{
Accumulation of a Last Deglacial Gravel Layer at Diexi, Eastern Tibetan Plateau and its Possible Seismic Significance
}

\author{
Siqi Zhang ${ }^{1,2}$, Hanchao Jiang ${ }^{1 *}$, Jiawei Fan ${ }^{1}$, Hongyan $\mathrm{Xu}^{1}$, Wei Shi ${ }^{1}$, Qiaoqiao Guo ${ }^{1}$ and \\ Xiaotong Wei ${ }^{1}$
}

${ }^{1}$ State Key Laboratory of Earthquake Dynamics, Institute of Geology, China Earthquake Administration, Beijing, China, ${ }^{2}$ College of Earth and Planetary Sciences, University of the Chinese Academy of Sciences, Beijing, China

Tectonic and climatic process controlling gravel accumulation in tectonically active regions is the subject of active debate. In this study, the formation mechanism of a gravel layer in the Diexi lacustrine section, eastern Tibetan Plateau, was investigated using mutually validated dating methods and detailed analysis of sedimentary processes. Optically stimulated luminescence (OSL) and accelerator mass spectrometry (AMS) ${ }^{14} \mathrm{C}$ dating

OPEN ACCESS

Edited by: David K. Wright, University of Oslo, Norway

Reviewed by:

Weiming Liu,

Institute of Mountain Hazards and Environment (CAS), China

Fuyuan An,

Qinghai Normal University, China

${ }^{*}$ Correspondence: Hanchao Jiang hcjiang@ies.ac.cn

Specialty section:

This article was submitted to

Quaternary Science, Geomorphology

and Paleoenvironment,

a section of the journal

Frontiers in Earth Science

Received: 19 October 2021 Accepted: 06 December 2021 Published: 23 December 2021

Citation:

Zhang S, Jiang H, Fan J, Xu H, Shi W,

Guo $Q$ and Wei X (2021) Accumulation

of a Last Deglacial Gravel Layer at

Diexi, Eastern Tibetan Plateau and its

Possible Seismic Significance.

Front. Earth Sci. 9:797732.

doi: 10.3389/feart.2021.797732 show that the gravel layer in the Diexi section accumulated at approximately $16.79 \mathrm{ka} \mathrm{BP}$. The sedimentary characteristics of the gravel layer and the contact between upper and lower strata indicate that the formation of the Diexi gravel layer was triggered by an earthquake rather than by a debris flow caused by torrential rain. And the result based on the intensity attenuation model are consistent with the characteristics of frequent large earthquakes in Diexi area. Detailed analysis of satellite images and sedimentary characteristics of the gravel layer provide evidence for an ancient landslide, which may be related to the gravel layer at Muer village (to the north of the Diexi section). Overall, this study reconstructs a gravel event at approximately $16.79 \mathrm{ka} \mathrm{BP}$ and has important theoretical and practical significance for understanding the formation mechanism of gravel deposits and analysing seismic events through gravel accumulation.

Keywords: gravel layer genesis, landslide, last deglacial lacustrine sediments, intensity attenuation model, eastern Tibetan Plateau

\section{INTRODUCTION}

Tectonic activity across the Tibetan Plateau (TP) has shaped the geology and landscape of western China and generated an abundance of thick gravel sediments (Li, 1991; Liu et al., 1996). In this context, the gravel deposits in western China should reflect the tectonic activities and denudation of the mountains (e.g., Wang et al., 2004; Sun, 2005; Guan et al., 2011; Li et al., 2014a; Wang et al., 2015; Li et al., 2017). On the other hand, glaciers also transport large amounts of gravel sediment including boulders, and gravel deposits have been used to reconstruct glacial history (e.g., Finkel et al., 2003; Kong et al., 2009, 2011; Heyman et al., 2011; Xu and Zhou, 2014). Thus, gravel sediments in and around the TP attract a growing number of studies.

In the past decade, five strong earthquakes (Wenchuan in 2008, Yushu in 2010; Lushan in 2013, Jiuzhaigou in 2017, Maduo in 2021) have occurred on the eastern margin of the TP. Earthquakes often destroy the bedrock structure in mountainous areas, resulting in wide occurrence of dense 
joints and leaving potential dangers for landslides (Su et al., 2017; Chen and $\mathrm{Wu}, 2018)$. Specifically, earthquakes are observed to have directly caused extensive landslides in the upper reach of Min River (Xu et al., 2013; Ma et al., 2018; Ren et al., 2018; Zhao et al., 2019). The landslides generally blocked the Min River and its tributaries, resulting in extensive deposition of dammed lakes (Wang et al., 2011; Wang et al., 2012). Recent studies with highresolution grain size, magnetic susceptibility, XRF and pollen records of lacustrine deposits show that, seismic activity exerted a major control on lacustrine deposition (Jiang et al., 2014; Jiang et al., 2017; Liang and Jiang, 2017; Xu et al., 2020; Wei et al., 2021). This is well consistent with frequent occurrence of the seismic activities revealed by various soft sediment deformations (SSDs) widely observed in the field (Wang et al., 2011; Xu et al., 2015; Jiang et al., 2016; Zhong, 2018).

What's more, the dam-break of barrier lake deposits often produces outburst deposits (Ma et al., 2018), which are well displayed on the surface structure of quartz particles (Chen et al., 2019). Previous studies suggested that the gravel accumulation in the eastern TP is of fluvial or flood origin (Wang et al., 2007; Chen et al., 2019; Xu et al., 2020). In this study, the gravel layer of the Diexi lacustrine section in the eastern $\mathrm{TP}$ is investigated to determine its genesis, sedimentological process, and connection with landslides and earthquakes. This study is of great significance for the reconstruction of gravel events in the tectonically active regions.

\section{GEOLOGICAL AND GEOGRAPHICAL SETTINGS}

Several active faults along the Longmenshan fault zone separate the TP from the Sichuan Basin (Zhang et al., 2003; Zhang, 2008). The eastward growth of the TP was restricted by the Sichuan Basin, leading to the rise of the Longmen Mountains (Xu et al., 2008). This area is a tectonically active zone on the eastern margin of the TP with frequent earthquakes. Mao county is located at the northern end of the Longmenshan fault. Active tectonism in this area is mainly controlled by the Minjiang (strike N-S), Songpinggou (strike NW-SE) and Maoxian-Wenchuan (strike NE-SW) faults (Tang et al., 1983; Chen et al., 1994; Si and Liu, 2008).

The Diexi area in Mao country has been affected by several earthquakes larger than $M_{s} 4.7$ in recent decades. Among them, the $1713 \mathrm{M}_{\mathrm{s}} 7.0$ and $1933 \mathrm{M}_{\mathrm{s}} 7.5$ earthquakes in Diexi were the most famous in this area. The Songpinggou fault is considered the seismogenic fault of the Diexi $M_{s} 7.5$ earthquake in 1933 (e.g., Ren et al., 2018). The landscape near Diexi town in Mao County is composed of typical alpines and valleys. The Min River flows from north to south, and Diexi Lake formed here. The valley cutting depth is more than $800 \mathrm{~m}$, and the maximum cutting depth can reach 3,000 $\mathrm{m}$ (Jiang et al., 2014). The epicentre of the 1933 Diexi earthquake, where the Songpinggou fault and Minjiang fault converge (Wang et al., 2014a; Ma et al., 2018), is approximately $5.5 \mathrm{~km}$ southwest of the Diexi section. Landslides triggered by the Diexi earthquake are mainly distributed in Songpinggou; in addition, some landslides occurred near Diexi town (Ren et al., 2018). Previous studies revealed that large amounts of clastic boulders are widely distributed across this area and have a maximum diameter of 5-8 m (Ma et al., 2018).

The Diexi section is located on the east bank of Diexi Lake in Mao country, Sichuan Province, where a continuous lacustrine sequence is exposed (Figure 1, 32 $4.5^{\prime} \mathrm{N} 103^{\circ} 43^{\prime} \mathrm{E}, 2,275 \mathrm{~m}$ a.s.l). Field observations show that some environmental event should have ended lacustrine sediments in the Diexi section. The section exposes more clearly with incision of the Min River and drop of water level. Muer village located on the west bank of the Diexi Lake with a horizontal distance of about $1 \mathrm{~km}$ from the Diexi section. The village is located on a platform $(\sim 2,520 \mathrm{~m}$ a.s.l) with an area of about $1.5 \mathrm{~km}^{2}$ and surrounded by mountains on three sides. The bedrock around the section is the Middle Triassic Zagunao Formation. The lithology of the upper member of the Zagunao Formation is grey to dark grey medium-to thick-bedded fine-grained calcareous quartz sandstone with massive structures intercalated with minor silty slates and slates. The lithology of the lower member is grey calcareous quartz fine sandstone (or greengrey tuffaceous sandstone) interbedded with a small amount of dark grey silty slate and grey black lenticular thin-bedded crystalline limestone of unequal thickness. In this study, we analyse a poorly sorted and subangular gravel layer present at a depth of approximately $14.80 \mathrm{~m}$ in the Diexi lacustrine section.

\section{MATERIALS AND METHODS}

\section{Chronology}

Radiocarbon $\left({ }^{14} \mathrm{C}\right)$ and optically stimulated luminescence (OSL) dating are commonly used methods for quantifying the depositional age of late Pleistocene lacustrine sediments. To determine the age of the gravel layer in the Diexi section, we collected three carbon samples, 17DX-C-08 at $9.98 \mathrm{~m}, 18 \mathrm{DX}-\mathrm{C}$ -08 at $14.15 \mathrm{~m}$ and $17 \mathrm{DX}-\mathrm{C}-10$ at $17.50 \mathrm{~m}$ (Table 2). Moreover, we also collected two OSL samples, 17DX-OSL-07 at $13.50 \mathrm{~m}$ and 17DX-OSL-08 at $16.37 \mathrm{~m}$ (Table 3). The carbon samples are all large charcoals with a particle size of approximately $0.2-0.5 \mathrm{~cm}$. Some samples (18DX-C-08) are treated with acid and alkali to decompose into slender charcoal chips. The charcoal with a large particle size indicates that it is transported within a regional scope or near the ground, excluding the possibility of long-distance transportation. Radiocarbon $\left({ }^{14} \mathrm{C}\right)$ dating measurements were performed in the Beta Laboratory, University of California, Irvine, USA. The radiocarbon ages are calibrated by Reimer et al. (2020).

The OSL samples equivalent dose were measured at Linyi University. 63-90 $\mu \mathrm{m}$ middle grain quartz (MQ) fractions (sieving, $10 \% \mathrm{HCl}, 10 \% \mathrm{H}_{2} \mathrm{O}_{2}$, etching with $40 \% \mathrm{HF}$, followed by immersion in $10 \% \mathrm{HCl}$ ). The purity of the quartz extracts was confirmed by the absence of an IRSL signal. The sample De values were measured on a Risø TL/OSL Reader model DA-20 equipped with a calibrated ${ }^{90} \mathrm{Sr} /{ }^{90} \mathrm{Y}$ beta radiation source (dose rate $0.1070 \mathrm{~Gy} / \mathrm{s}$ for MQ in the standard configuration), blue $\left(470 \pm 30 \mathrm{~nm} ; \sim 102 \mathrm{~mW} / \mathrm{cm}^{2}\right)$ and infrared $(880 \pm 40 \mathrm{~nm}$, $\sim 173 \mathrm{~mW} / \mathrm{cm}^{2}$ ) light sources, and detection through a $7-\mathrm{mm}$ 

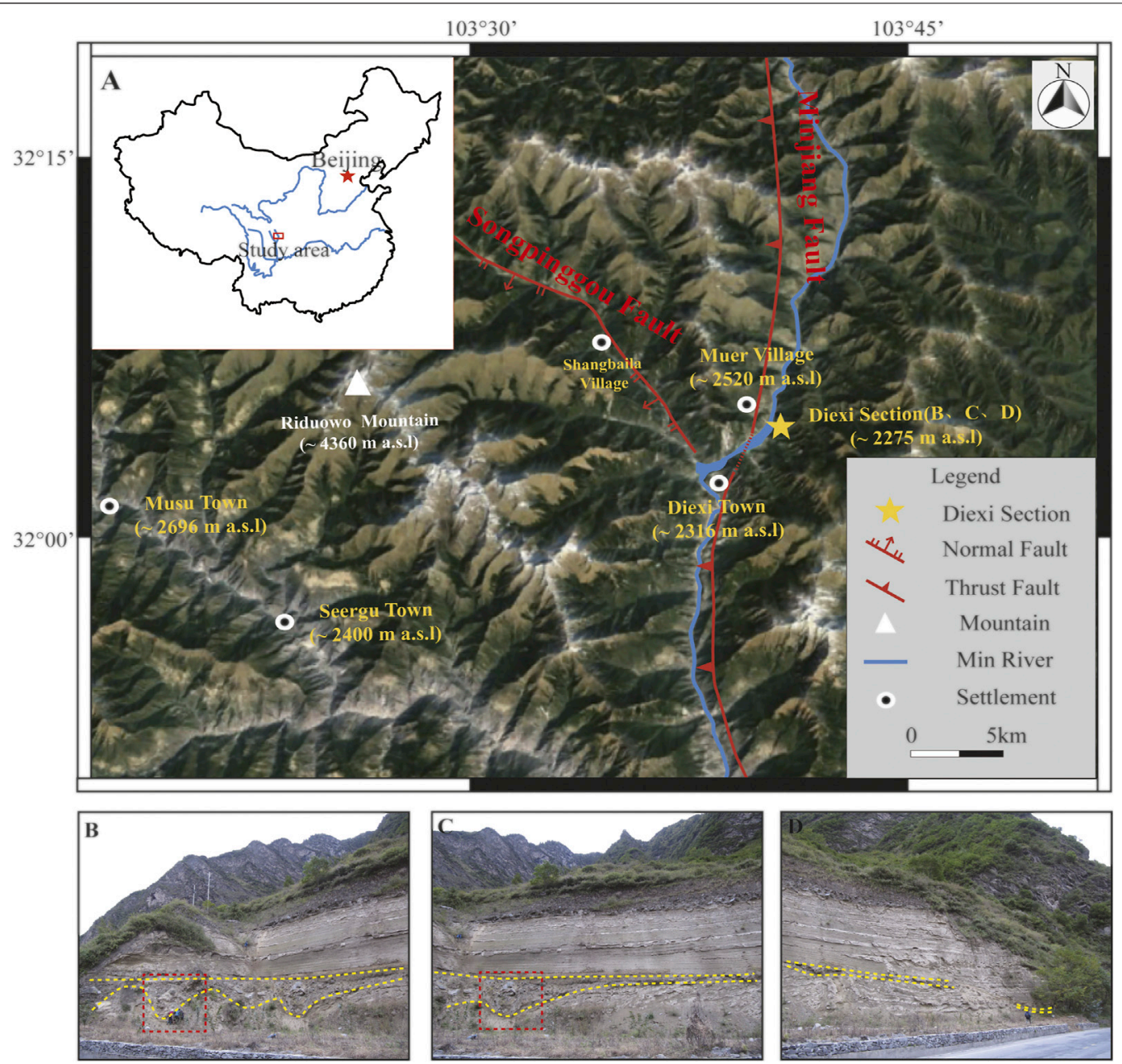

FIGURE 1 | (A) Diexi lacustrine section close to Diexi town, where the Songpinggou fault and Minjiang fault converge; (B) Northern part of the section, and the red dotted line represents the position of Figure 4B; (C) Central part of the section, and the red dotted line represents the position of Figure 4A; (D) Southern part of the section

TABLE 1 | The attenuation model (Lei et al., 2007).

\begin{tabular}{|c|c|c|c|c|c|c|}
\hline Area & Axial direction & $d_{1}$ & $d_{2}$ & $d_{3}$ & $\mathbf{R}_{0}$ & $\sigma$ \\
\hline \multirow[t]{3}{*}{ Southwest of Sichuan } & Long axis & 7.3568 & 1.2780 & -5.0655 & 24 & 0.70 \\
\hline & Short axis & 3.9502 & 1.2780 & -3.7567 & 9 & 0.70 \\
\hline & mean axis & 5.3603 & 1.2963 & -4.3666 & 15 & 0.51 \\
\hline \multirow[t]{3}{*}{ Sichuan basin } & Long axis & 4.0293 & 1.3003 & -3.6404 & 10 & 0.45 \\
\hline & Short axis & 2.3816 & 1.3003 & -2.8573 & 5 & 0.45 \\
\hline & mean axis & 3.3727 & 1.2755 & -3.2858 & 7 & 0.42 \\
\hline
\end{tabular}

TABLE 2 | Results of AMS ${ }^{14} \mathrm{C}$ dating for the Diexi lacustrine sediments (Reimer et al., 2020).

\begin{tabular}{|c|c|c|c|c|c|c|}
\hline Sample & Number & Depth (m) & Dated material & $\delta^{13} \mathrm{C}$ & AMS ${ }^{14} \mathrm{C}$ Age $/{ }^{14} \mathrm{C}$ yr BP & $\begin{array}{c}\text { Adjusted age/cal } \\
\text { yr BP }\end{array}$ \\
\hline 17DX-C-08 & 478062 & 9.98 & charcoal & -22.7 & $13,560 \pm 40$ & $16,533-16,223$ \\
\hline 18DX-C -08 & 492291 & 14.15 & charcoal & -22.7 & $13,670 \pm 40$ & $16,685-16,347$ \\
\hline $17 D X-C-10$ & 478064 & 17.5 & charcoal & -20.5 & $14,150 \pm 50$ & $17,362-17,064$ \\
\hline
\end{tabular}



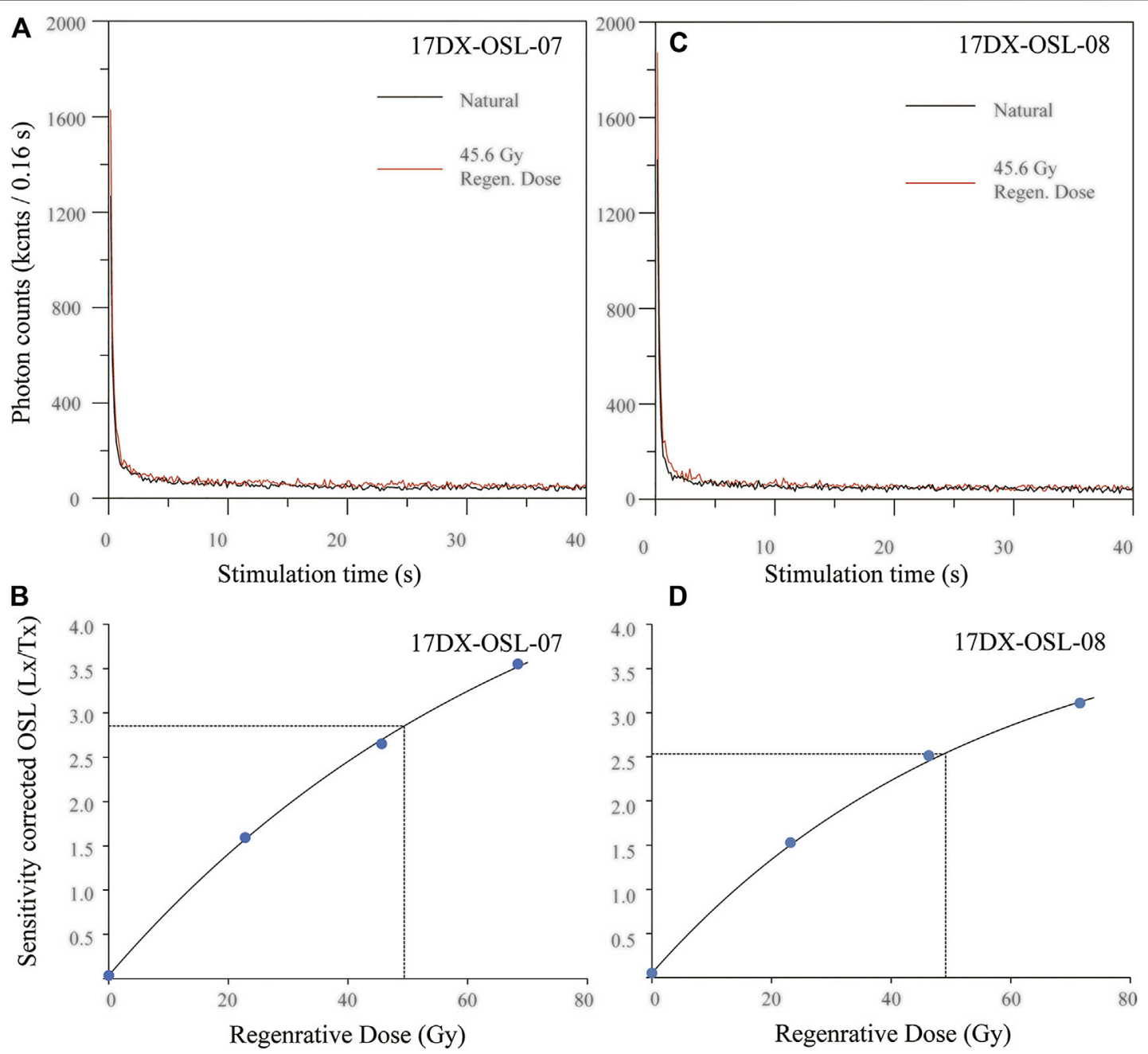

FIGURE 2 | (A) OSL decay curves for natural dose and regenerative dose of 48.6 Gy of 17DX-OSL-07; (B) Dose response curve of 17DX-OSL-07; (C) OSL decay curves for natural dose and regenerative dose of 48.6 Gy of 17DX-OSL-08; (D) Dose response curve of 17DX-OSL-08.

thick U-340 glass filter. Single-aliquot regenerative (SAR) protocol (Murray and Wintle, 2000, 2003) was used for quartz measurement. De values were calculated using the sum of photons detected in the first $0.9 \mathrm{~s}$ of the stimulation minus firstly background of the OSL decay curve. The aliquots were rejected that recycling ratio were not consistent within $10 \%$ of unity and recuperation were larger than $5 \%$. The aliquots De over-dispersion was less than $20 \%$, so the center age model (CAM) was used in equivalent dose calculation (Arnold and Roberts, 2009). OSL decay curves and dose response curves of two samples as shown in Figure 2.

Dose Rate were measured at the State Key Laboratory of Earthquake Dynamics, Institute of Geology, China Earthquake Administration. The $\mathrm{U}, \mathrm{Th}$, and $\mathrm{K}$ activity concentrations were measured by high resolution gamma spectrometry (ORTEC GEM70P4-95 P). The dose rate is calculated directly by using the observed radionuclide activity concentration and attenuation values from (Aitken, 1998). Besides, the water content of the sample and cosmic ray contribution was considered for accurate calculation of the environmental dose (Prescott and Hutton, 1994).

\section{The Intensity Attenuation Model}

Intensity attenuation model is an important method to study seismic activity (e.g., Bakun and Wentworth, 1997; Chandler and Lam, 2002; Sorensen et al., 2009; Allen et al., 2012). The seismic attenuation model is useful for earthquake prevention and mitigation, especially in western Sichuan, which is a tectonically active area in China. In recent years, the intensity attenuation model has been studied in detail in China (e.g., Wang et al., 2000; Lei et al., 2007; Sun, 2011; Xiao and Yu, 2011).

The general form of the intensity attenuation model formula is:

Long axis: $I_{a}=d_{a 1}+d_{a 2} M+d_{a 3} \log \left(R_{a}+R_{a 0}\right)+\varepsilon_{a}$

Short axis : $I_{b}=d_{b 1}+d_{b 2} M+d_{b 3} \log \left(R_{b}+R_{b 0}\right)+\varepsilon_{b}$ where $I$ is the intensity of the modified Mercalli intensity (MMI), $M$ is the magnitude $\left(\mathrm{M}_{\mathrm{s}}\right)$, and $R$ is the epicentral distance. $R_{\mathrm{a} 0}$ and $R_{\mathrm{b} 0}$ are near-field saturation factors along the long and short 
TABLE 3 | Results of OSL dating for the Diexi lacustrine sediments.

\begin{tabular}{|c|c|c|c|c|c|c|c|c|c|c|}
\hline Sample & $\begin{array}{l}\text { Depth } \\
\text { (m) }\end{array}$ & $\begin{array}{c}\text { Water } \\
\text { content } \\
(\%)\end{array}$ & ${ }^{238} \mathrm{U}(\mathrm{Bq} / \mathrm{kg})$ & $\begin{array}{c}{ }^{232} \mathrm{Th} \\
(\mathrm{Bq} / \mathrm{kg})\end{array}$ & $\begin{array}{c}{ }^{226} \mathrm{Ra} \\
(\mathrm{Bq} / \mathrm{kg})\end{array}$ & ${ }^{40} \mathrm{~K}(\mathrm{~Bq} / \mathrm{kg})$ & $\begin{array}{l}\text { Dose } \\
\text { rate } \\
\text { (Gy/ka) }\end{array}$ & $n / N$ & $\begin{array}{l}\text { Equivalent } \\
\text { dose } \\
\text { (Gy) }\end{array}$ & $\begin{array}{l}\text { OSL age } \\
\text { (ka) }\end{array}$ \\
\hline 17DX- & 16.37 & $30 \pm 5$ & $26.6 \pm 5.8$ & $35.8 \pm 0.4$ & $24.0 \pm 0.4$ & $438.4 \pm 8.0$ & $2.33 \pm 0.1$ & $18 / 24$ & $39.75 \pm 0.6$ & $17.04 \pm 0.73$ \\
\hline
\end{tabular}

OSL-08

Note: " $n$ " represents the number of accepted aliquots that passed the SAR, rejection criteria and used for De determination; "N" represents total number of aliquots measured.

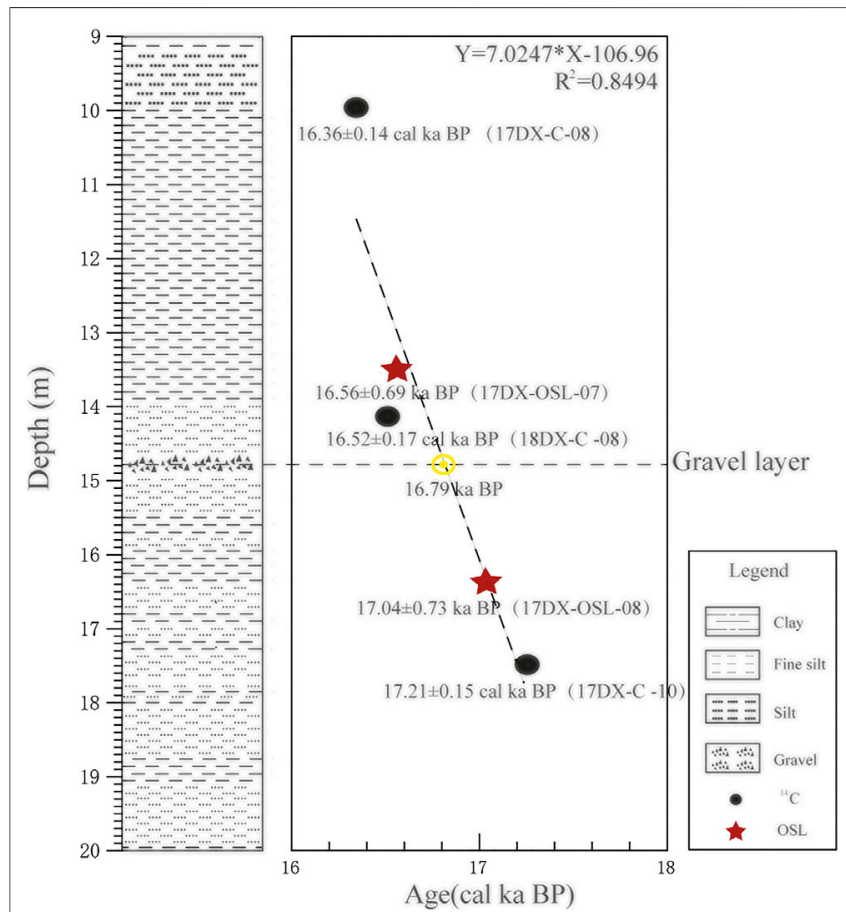

FIGURE 3 | Age vs. stratigraphic depth of the Diexi lacustrine section.

axes, respectively. $d_{a 1}, d_{a 2}$, and $d_{a 3}$ and $d_{b 1}, d_{b 2}$, and $d_{b 3}$ are regression constants, and $\varepsilon_{a}$ and $\varepsilon_{b}$ are residuals with means of zero, representing uncertainties.

In previous studies of the paleoseismic records, the constraints of the magnitudes are poor (e.g., Marco et al., 1996; Begin et al., 2005; Ferry et al., 2011). In recent years, some researchers have applied the intensity attenuation model to the study of the paleoseismic records about the sediments, and reconstructed the continuous paleoseismic record (e.g., Kremer et al., 2017; Lu et al., 2020). Although the accurate estimation of the magnitude based on a single station is difficult, but it is possible to use the intensity attenuation model to give a relatively credible lower magnitude limit of the paleoseismic event (Lu et al., 2020). This allows signals of large earthquakes to be captured in sediment record. Therefore, the application of intensity attenuation model plays an important role in the reconstruction of paleoseismic events.
Different seismic faults have different abilities to disrupt the surface, and the attenuation relationship of seismic intensity is quite variable. Compared with the previous attenuation models, the model by Lei et al. (2007) for western Sichuan is consistent with the characteristics of mountainous regions with steep valleys and long, narrow faults (Table 1). Accordingly, this study used the intensity attenuation model developed by Lei et al. (2007) to constrain the lower magnitude limit of the paleoseismic event.

\section{RESULTS}

\section{Chronology of the Gravel Layer}

The charcoal samples in the section produce three radiocarbon ages, which are $16.36 \pm 0.14 \mathrm{cal}$. $\mathrm{ka} \mathrm{BP}$ at $9.98 \mathrm{~m}$ (17DX-C-08), $16.52 \pm 0.17$ cal. $\mathrm{ka} \mathrm{BP}$ at $14.15 \mathrm{~m}(18 \mathrm{DX}-\mathrm{C}-08)$ and $17.21 \pm$ 0.15 cal. ka BP at $17.50 \mathrm{~m}$ (17DX-C-10). Based on three radiocarbon ages, we get the age of the gravel layer is $\sim 16.80 \mathrm{ka}$ BP. On the other hand, the OSL samples in the section produce two ages of $16.5 \pm 1.3 \mathrm{ka} \mathrm{BP}$ at $13.50 \mathrm{~m}$ (17DXOSL-07) and $17.0 \pm 0.7 \mathrm{ka} \mathrm{BP}$ at $16.37 \mathrm{~m}$ (17DX-OSL-08). Based on two OSL ages, we get the age of the gravel layer is $\sim 16.5 \mathrm{ka}$ BP. The chronological results show that they have a good linear relationship (Tables 2 and 3; Figure 3).

Previous studies show that the deposition rate of the lacustrine deposits in the study area was relatively slow (Jiang et al., 2014, Jiang et al., 2017; Liang and Jiang, 2017; Wei et al., 2021; Shi et al., 2020). Compared with fine particle deposition, the gravel layer was deposited instantaneously. Therefore, when we use the ages for linear fitting, we regard the age represented by the gravel event as a point, and we deduct the thickness of the gravel layer. Based on the five ages obtained, the ages of fine-grained deposition were calculated to obtain the age of the gravel layer, which was approximately $16.79 \mathrm{ka} \mathrm{BP}\left(R^{2}=0.85\right)$. We consider this result to be credible.

\section{Sedimentary Characteristics of the Gravel Layer}

The gravel layer in the Diexi section was studied in detail (Figure 4). The gravel in the layer is mainly grey to dark grey fine-grained quartz sandstone with a small amount of silty slate, which is similar in composition to the local bedrock. The gravel layer is predominately composed of gravel fragments with a range of different sizes, including plate gravel and block gravel. The 

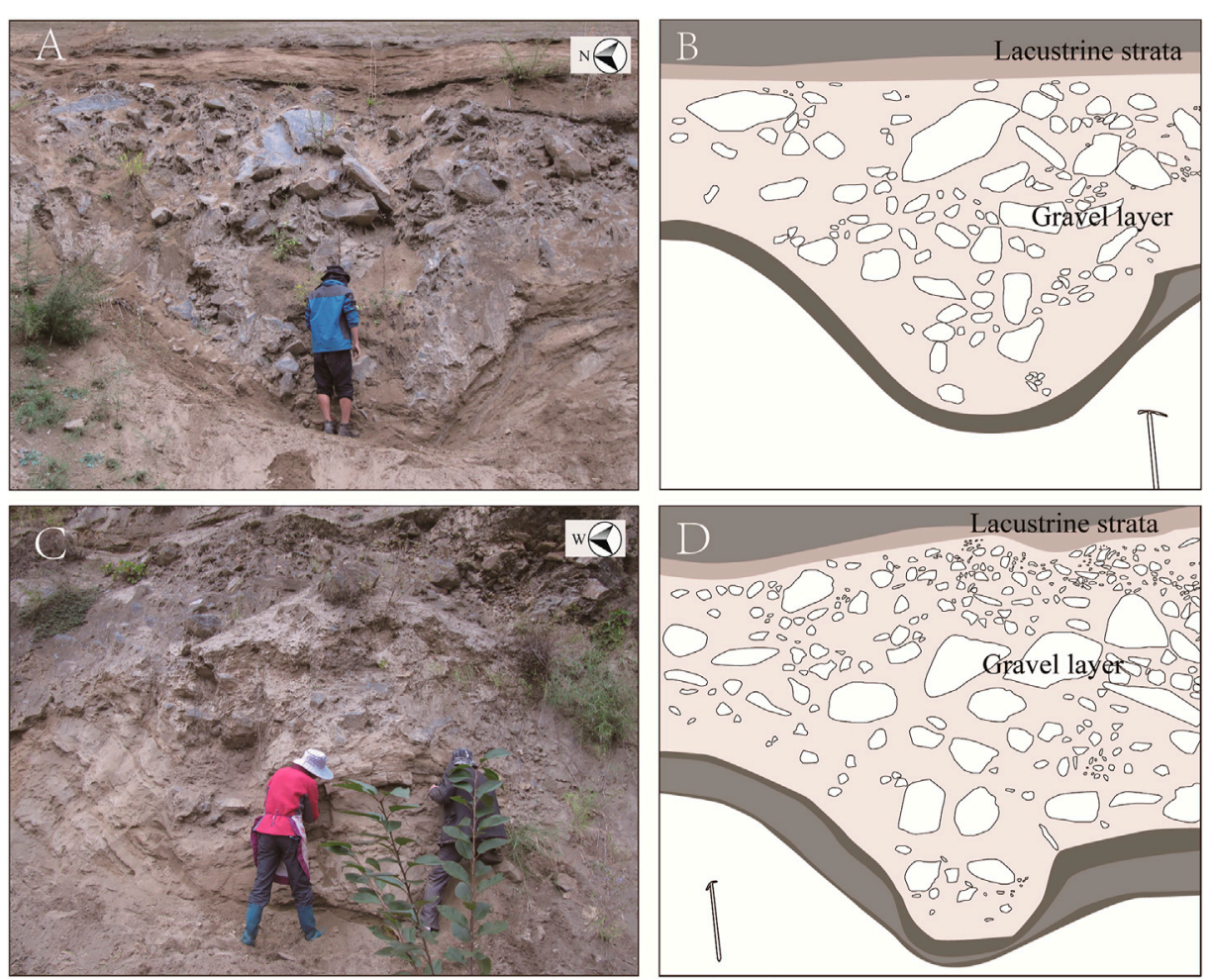

FIGURE 4 | (A) V-shaped bending of the underlying lacustrine layer due to boulder impact in the northern part of the section; (B) Sketch of the V-shaped bending in the northern part of the section; (C) V-shaped bending of the underlying lacustrine layer due to boulder impact in the middle part of the section; (D) Sketch of the $\mathrm{V}$-shaped bending in the middle part of the section.

diameter of exposed gravel ranges from approximately $2 \mathrm{~cm}$ to $1.5 \mathrm{~m}$ and appears to be barely sorted. The gravel is poorly rounded. The clasts are distributed with almost no order. The gravel layer contains little mud or silt as a matrix, and the sediments are clast-supported (Figures 4A,C).

The gravels in the northern part and middle of the section are mostly boulders. The boulders exposed on this side are poorly sorted. The boulders exposed at the northern end mostly have diameters of $0.5-0.75 \mathrm{~m}$, and the maximum diameter is $0.8 \mathrm{~m}$ (Figure 4A). The boulders in the middle mostly have diameters of approximately $0.5 \mathrm{~m}$, and the maximum diameter reaches $1 \mathrm{~m}$ (Figure 4C). At the southern end of the section, the gravels mostly have diameters of approximately $0.02 \mathrm{~m}$, and no large boulder is present. As a whole, the gravel layer extends for approximately $20 \mathrm{~m}$ and becomes gradually thinner from north $(\sim 4 \mathrm{~m})$ to south $(\sim 0.2 \mathrm{~m})$ (Figures 1B-D). At the southern end of the Diexi section, the lacustrine layer is collapsed, and part of the gravel layer is not visible. Further to the south, the lacustrine layer and the gravel layer are exposed again with stratigraphic correlation along the strike, confirming that the outcrops are part of the same formation. The large gravels are concentrated in the north and decrease towards the south. At the southern end of the section, the gravel is still clast-supported and poorly rounded.

\section{Contact Between the Gravel Layer and the Lacustrine Layer and Soft Sediment Deformation}

The gravel layer is directly overlain by a lacustrine layer composed of clay-silt material. There is no fining-upward gradation of particles or sedimentation bedding between the lacustrine and gravel layers (Figures 5B,C). The lacustrine layer under the gravel layer is severely disturbed, especially in the middle and northern sections (Figure 4), but it can be continuously traced across the outcrop and shows no signs of erosion by collapsed debris. The lacustrine layer underlying the gravel layer has obvious $\mathrm{V}$-shaped bending deformation in the northern part and middle of the section, and the sedimentary bedding is parallel to the bending interface containing $\mathrm{V}$-shaped bending and is accompanied by obvious interlayer sliding. The scale of the lacustrine bending structures is approximately $2-3 \mathrm{~m}$ (Figures 4B,D). Compared with the lacustrine layer without deformation, the lacustrine layer at the bent part is obviously thinned, and no lacustrine layer loss is caused by boulder erosion. 


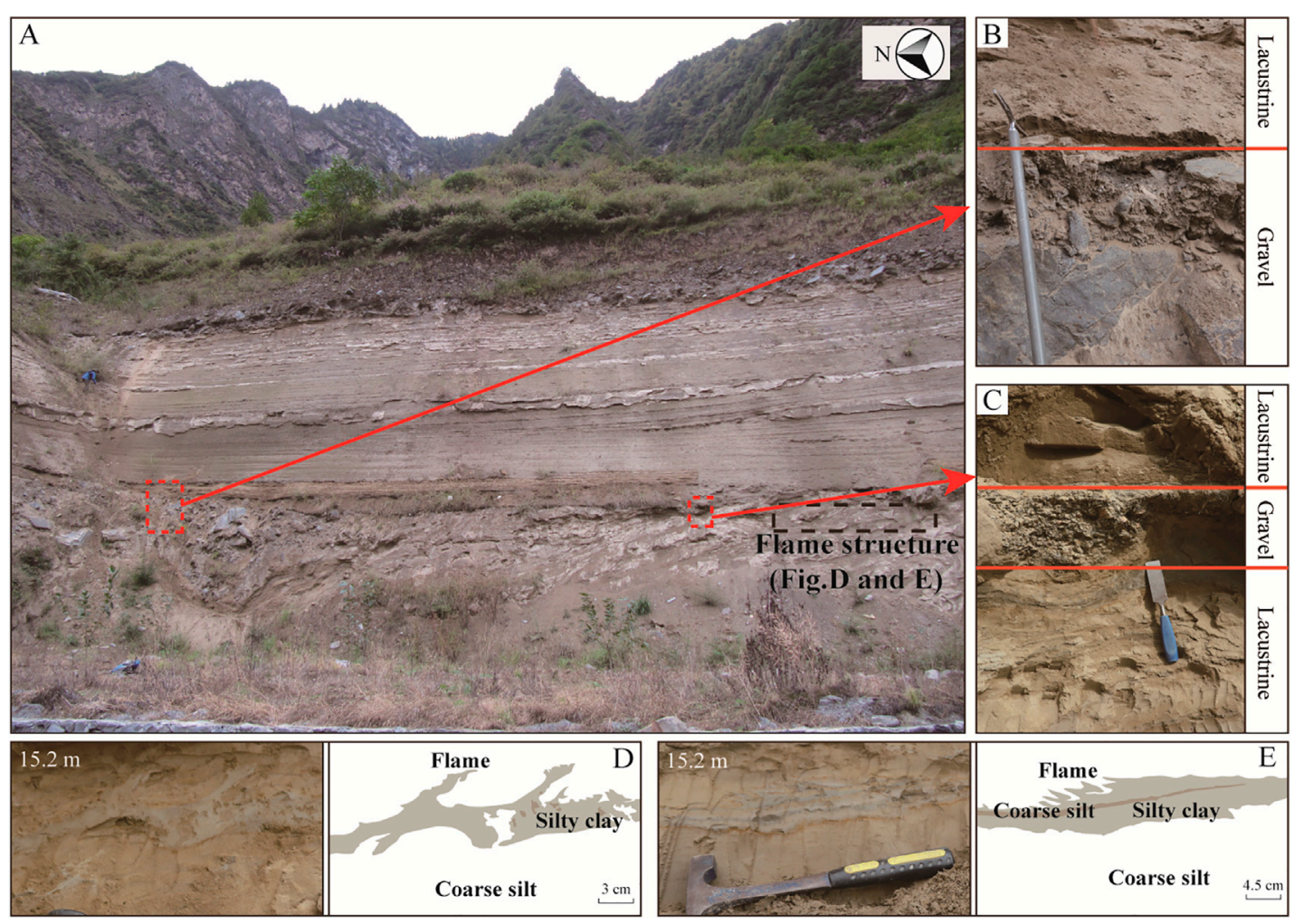

FIGURE 5 | (A) The central part of Diexi section; (B) and (C) Lacustrine layer in direct contact with the gravel layer; (D) and (E) SSD layer approximately $40 \mathrm{~cm}$ below the gravel layer, showing a typical flame structure.

In the lacustrine sediments of the Diexi section, we identify a layer of flame structures with heights of 3-6 cm, approximately $40 \mathrm{~cm}$ beneath the gravel layer in the middle of the section, and can be traced laterally across the entire section (Figures 5D,E). Flame structures are directed upward at a very high angle. The mudstone laminae forming the flame shapes are typically $1.5 \mathrm{~cm}$ thick, but in the flamed portions, the thickness is approximately $3 \mathrm{~cm}$. This deformation can be caused by earthquakes.

\section{Assessment of the Gravel Event by Intensity Attenuation Models}

Given that the Diexi area has had several large earthquakes in the recorded history, leaving extensive landslide residue in the area (Ren et al., 2018), we believe that there is a considerable possibility that the gravel event was triggered by an earthquake. Therefore, we use the intensity attenuation model to evaluate the level of this event.

Earthquake-induced landslides are closely related to earthquake magnitude and epicentre distance (Keefer, 1984). The intensity attenuation model is based on the magnitude, epicentral distance and local intensity. Therefore, to study the magnitude of the earthquake that triggered the landslide based on the intensity attenuation model, we consider the local intensity that the landslide response and the approximate distance of the earthquake epicentre.
$\mathrm{A} \mathrm{M}_{\mathrm{w}} 6.6$ earthquake in Japan in 2018 produced thousands of coseismic landslides, most of which occurred in regions with an intensity of MMI VII to VIII (Zhang et al., 2019). Zhou and Zhang (1994) counted the landslides generated by 11 earthquakes in Southwest China since 1970, and the results indicate that new landslides generally did not occur at the MMI $\leq \mathrm{VI}$, and the minimum intensity triggering a new landslide was MMI VII. On the other hand, the SSD can be divided into linear waves, asymmetric billows, coherent vortices and broken breccia (Wetzler et al., 2010). The flame structures in the Diexi section are considered asymmetric billow deformation. The seismic intensity range corresponding to this deformation is between MMI VII and VIII (Lu et al., 2020), providing support for such a seismic intensity triggering the gravel layer above the flame structures in the Diexi section, although the lithology (and/or sediment compaction) of the Diexi sediments are significantly different from those in Lu et al. (2020). Accordingly, we use MMI > VII as the lower limit of the seismic intensity that triggered the landslide.

In the intersection zone of the Songpinggou fault and the Minjiang fault, the Jiaochang-Songpinggou area, approximately $5.5 \mathrm{~km}$ from Muer village, has witnessed many large earthquakes in the past (Chen et al., 1994; Ren et al., 2018). The most famous of these earthquakes are the $1713 \mathrm{M}_{\mathrm{s}} 7.0$ earthquake and the $1933 M_{s} 7.5$ earthquake, and the epicentres of both are close to Jiaochang village (China Earthquake Administration, 1999; Fan 

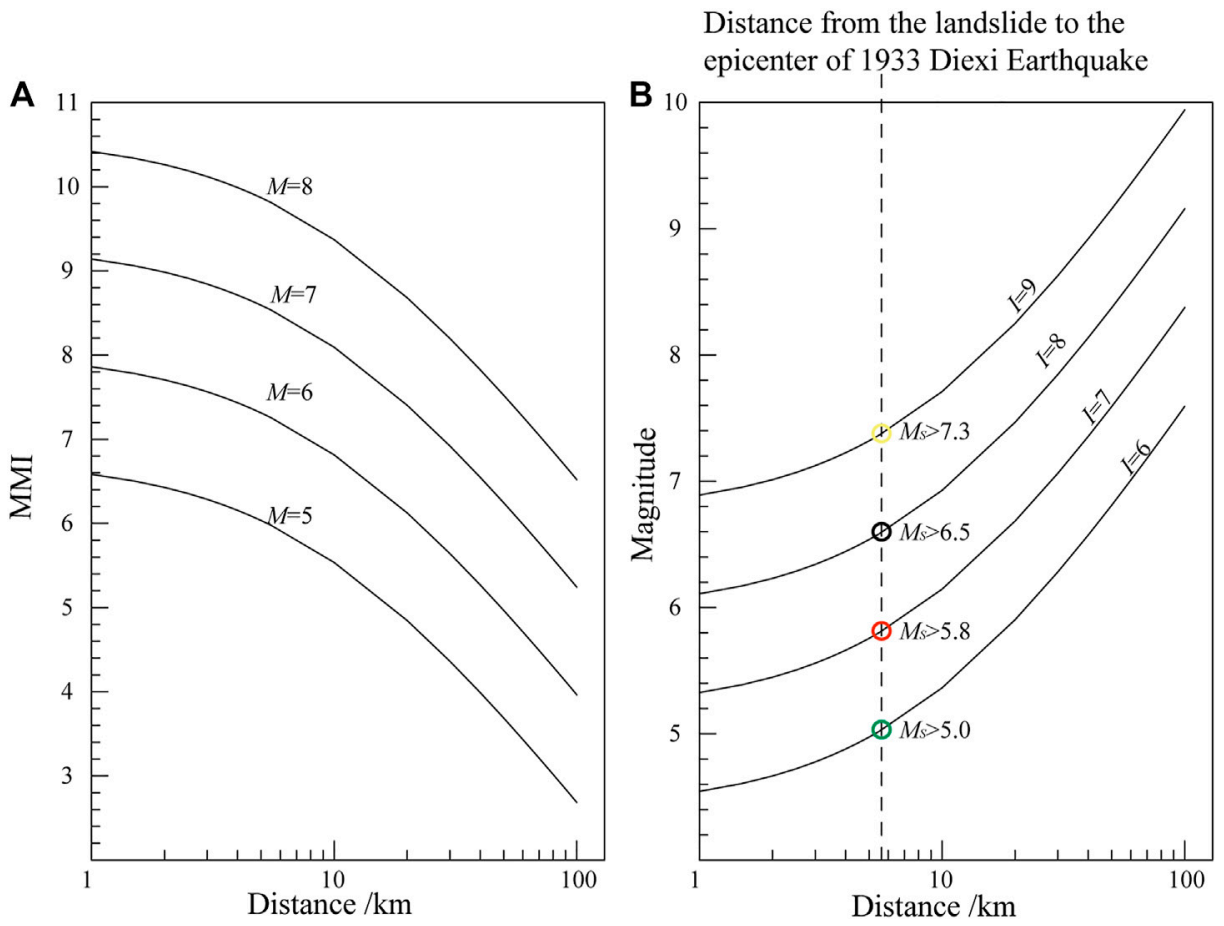

FIGURE 6 | (A) Attenuation model by Lei et al. (2007); (B) Relationship between $\mathrm{M}_{\mathbf{S}}$ and R based on different MMI values. The position of the dotted line represents the distance from the section to the epicentre of the 1933 Diexi earthquake.

et al., 2020). Landslide deposits are widely distributed in this area, including landslides triggered by the 1933 Diexi earthquake (Ren et al., 2018). Based on this, we use the distance from the epicentre of the 1933 Diexi earthquake to Muer Village $(5.5 \mathrm{~km})$ as the $\mathrm{R}$ to calculate the lower limit of the earthquake magnitude. According to the attenuation model of intensity, the magnitude corresponding to $\mathrm{MMI}>\mathrm{VII}$ is $\mathrm{M}_{\mathrm{s}}>5.7$ by taking $\mathrm{R}=$ $5.5 \mathrm{~km}$ (Figure 6).

In fact, the scale of the landslide in Muer village is relatively large, with a landslide area of more than $1 \mathrm{~km}^{2}$, which is close to the scale of the 1933 Diexi landslide. Landslides of this scale are more likely to occur in areas with seismic intensities of IX and greater than IX (Sun and Cai, 1997). Combined with the case of the Wenchuan earthquake, we further define the magnitude of the earthquake that triggered the landslide in Muer village. The LAP (Landslide Area Percentage in certain calculation windows) value about the Wenchuan earthquake increases gradually from the VII to XI intensity zone. The LAP value of the zone with the intensity $\geq$ VII is $0.91 \%$. Among them, the LAP value in the VIII intensity zone is $0.16 \%$, and for the IX intensity zone, it is $1.45 \%$ (Xu et al., 2013). The value of LAP increases significantly from the VIII intensity zone to the IX intensity zone. Meanwhile, the landslide concentration is 1.2 per $\mathrm{km}^{2}$ in the area with intensities $\mathrm{X}$ and XI. In the IX intensity zone it is 0.4 per $\mathrm{km}^{2}$, and this concentration decreases dramatically to 0.1 per $\mathrm{km}^{2}$ in the VIII intensity zone (Huang and Li, 2009). In fact, the seismic intensity in the study area reached VIII during the 2008 Wenchuan earthquake but no particularly large landslides were triggered locally (Huang and Li, 2009; Li et al., 2014b). Therefore, we believe that the probability of landslides in the region increases greatly after the seismic intensity reaches IX.

Considering the factors above, we believe that when the Muer village landslide occurred, the seismic intensity should have reached level IX or above in this area. The magnitude corresponding to MMI > IX is approximately $\mathrm{M}_{\mathrm{s}}>7.3$ by taking $\mathrm{R}=5.5 \mathrm{~km}$ (Figure 6). This result is close to the $\mathrm{M}_{\mathrm{s}}$ of the 1933 Diexi earthquake, which caused a large number of landslides in the study area.

\section{DISCUSSION}

Gravel layers are often linked with floods, rainstorms or earthquakes. The grain size of flood deposition has a process of upward coarsening and then forms a normal grain sequence with a decrease in flow intensity (Rubin et al., 1998; Wang et al., 2010). However, there is no such change between the gravel layer and the lacustrine layer in the Diexi section and the lacustrine layer is directly contact to large boulder. At the same time, the lithologic composition of the boulder in the Diexi section is similar to that of the local bedrock, and the degree of rounding and sorting are poor. These results indicate that most of the gravel was deposited without a long-distance transport.

The strong $\mathrm{V}$-shaped bending indicates that the lacustrine layers were impacted strongly by boulders as large as $2-3 \mathrm{~m}$ in diameter. From the V-shaped bending at the northern end of the section, the boulder disturbance severely affected the lacustrine sediments from north to south, and the impact dissipated within a 
distance of $\sim 20 \mathrm{~m}$. This bending of the underlying layer can occur during a landslide event, when large boulders run down hillsides and collide with unconsolidated lake floor sediments, causing liquefaction and generating large-scale folds that may be accompanied by small interlayer gliding (Wang et al., 2011). These observations indicate that the force moving these large boulders was instantaneous and explosive, and this force was mainly manifested by slip in the interlayer rather than laterally in the lacustrine layer. In studying the characteristics of gravel accumulation, we found that the gravel layer is clast-supported with almost no mud or silt. The underlying lacustrine layer shows a typical V-shaped curve but is not eroded.

The vast majority of rain-induced landslides usually occur in loose deposits, most of which contain large amounts of sand or clay (e.g., Tang et al., 2011; Wang et al., 2014b; Zhou et al., 2016). Moreover, heavy rains always input large amounts of clay and sand into the sedimentary system in mountainous areas (Chen et al., 2011; Oldrich et al., 2012). If heavy rain was involved in the formation of the gravel layers, it would have brought large amounts of silt and led to scour erosion of the underlying sediment layers. Most of the rain-induced landslides in western Sichuan were related to bedrock damage from earlier earthquakes (e.g. Su et al., 2017; Chen et al., 2020), and previous studies showed that the majority of landslides in the upper reach of Min River since the late Pleistocene were triggered by earthquakes instead of rainfall (e.g., Li et al., 2015; Ren et al., 2018). Therefore, relative to rainfall inducing, we believe that the gravel layer in the Diexi section is more likely to represent a seismic landslide event.

SSD structures can provide field evidence of earthquake activity. When the surface acceleration reaches $0.1 \mathrm{~g}$, it can lead to the liquefaction of loose underwater sediments and cause sedimentary disturbance and deformation. Near the epicentre of an $M_{s}=5$ earthquake, the surface acceleration can reach $0.1 \mathrm{~g}$ (Rodríguez-Pascua et al., 2000; Qiao and Li, 2009; Wetzler et al., 2010). As a typical SSD, flame structures can be produced by many factors, such as earthquakes, channel erosion, gravity slides, and permafrost (Zhong et al., 2019), but they have different features. Considering the local geological background with frequent earthquakes, the lacustrine sediments of the Diexi section are most vulnerable to earthquake due to lack of glaciation and storms. On the other hand, the wings of flame structures related to cryoturbation are usually symmetrical (Vandenberghe, 1992; Harris et al., 2000; Zhong et al., 2020a). But the flame structures in the Diexi section were formed when fine clays were squeezed into thicker sand layers, showed the characteristics of asymmetric billows deformation. Thirdly, the conduction of seismic waves leaves SSDs with transverse continuity in the Diexi lacustrine sediments (Jiang et al., 2016; Zhong et al., 2020b). However, the SSDs caused by the rain-induced landslides do not have this property. So the deformation in the Diexi section is most likely caused by earthquakes, which has also been discussed in some other areas in the TP (e.g., Jiang et al., 2014, 2016).

Previous studies have shown that in some other areas, rockfalls are widespread when $\mathrm{Ms} \geq 5.4$ and rock block slides occur when $M_{s} \geq 5.9$ (Rodri'guez et al., 1999). Moreover, the SSD approximately $40 \mathrm{~cm}$ below the gravel layer was likely caused by the same earthquake as the gravel layer, and the minimum earthquake magnitude that caused the SSD was $\mathrm{M}_{\mathrm{s}} 5.7$ (Monecke et al., 2006). These evidences suggest that the lower limit of the earthquake magnitude calculated based on the intensity attenuation model appears to be reliable. Furthermore, Diexi area had two major earthquakes in the historical record, $1713 \mathrm{M}_{\mathrm{s}}$ 7.0 earthquake and the $1933 \mathrm{M}_{\mathrm{s}} 7.5$ earthquake (China Earthquake Administration, 1999; Fan et al., 2020), both of which caused a large number of landslides in this area. Our study about the magnitudes based on the intensity attenuation model also seem to support the idea of a seismic trigger for landslides. If the landslide event was triggered by an earthquake, its magnitude would most likely be $M_{s}>7.3$ as evaluated above, and this is consistent with the frequent occurrence of large earthquakes in the Diexi area. Therefore, the gravel layer in the Diexi section could be formed by an earthquake-induced landslide.

To study the source of the landslide, we analysed the sedimentary characteristics of gravels at different positions in the section. The gravel layer gradually thins from the northern end to the southern end, while the average gravel size also gradually decreases, and the large boulder is mainly concentrated in the northern end of the section. The gravels are almost angular throughout the section and are better sorted in the southern end than in the northern end. These features indicate that the coarse-grained materials were transported from north to south, and the northern end of the section is closer to the paleo-landslide. In addition, the V-shaped bending of the lacustrine layer has different characteristics on each side (Figures 4B,D). Specifically, the lacustrine layer bends downward gently on the left but steeply on the right limb of the fold. Generally, the SSD structures caused by gravitational collapse are mainly concentrated along the front edge of the landslide, and deformation commonly has a dominant orientation, which is inclined to the position of the landslide mass (Wang et al., 2009). Therefore, the landslide impact probably came from the direction of the shallower side of the fold, causing compression and steepening of lacustrine sediments on the opposite flank. Combining all the sedimentological features, the landslide may have occurred in the mountains to the northwest of the section.

In summary, we believe that the gravel accumulation in the Diexi section may be related to an ancient landslide in the northwest of the section at $\sim 16.79 \mathrm{ka} \mathrm{BP}$. Based on these lines of evidence and detailed analysis of satellite images and field observations, we identified the remains of an ancient landslide at Muer village to the north of the Diexi section (Figure 7A). Here, poorly sorted angular gravels are widely distributed on the bedrock platform (Figures 7C,D). The gravel layer is directly overlain by lacustrine sediments (Figure 7C), and the contact between the gravel layer and lacustrine sediments is similar to that observed in the Diexi section. Except for one side facing the Min River, the other three sides of the platform are high mountains, which is a typical negative relief due to the partial collapse of slopes. These findings indicate that this region possibly experienced a large-scale landslide like the Jiaochao area (Ma et al., 2018; Zhao et al., 2019). Satellite images show that the surrounding mountains are currently covered by vegetation, 

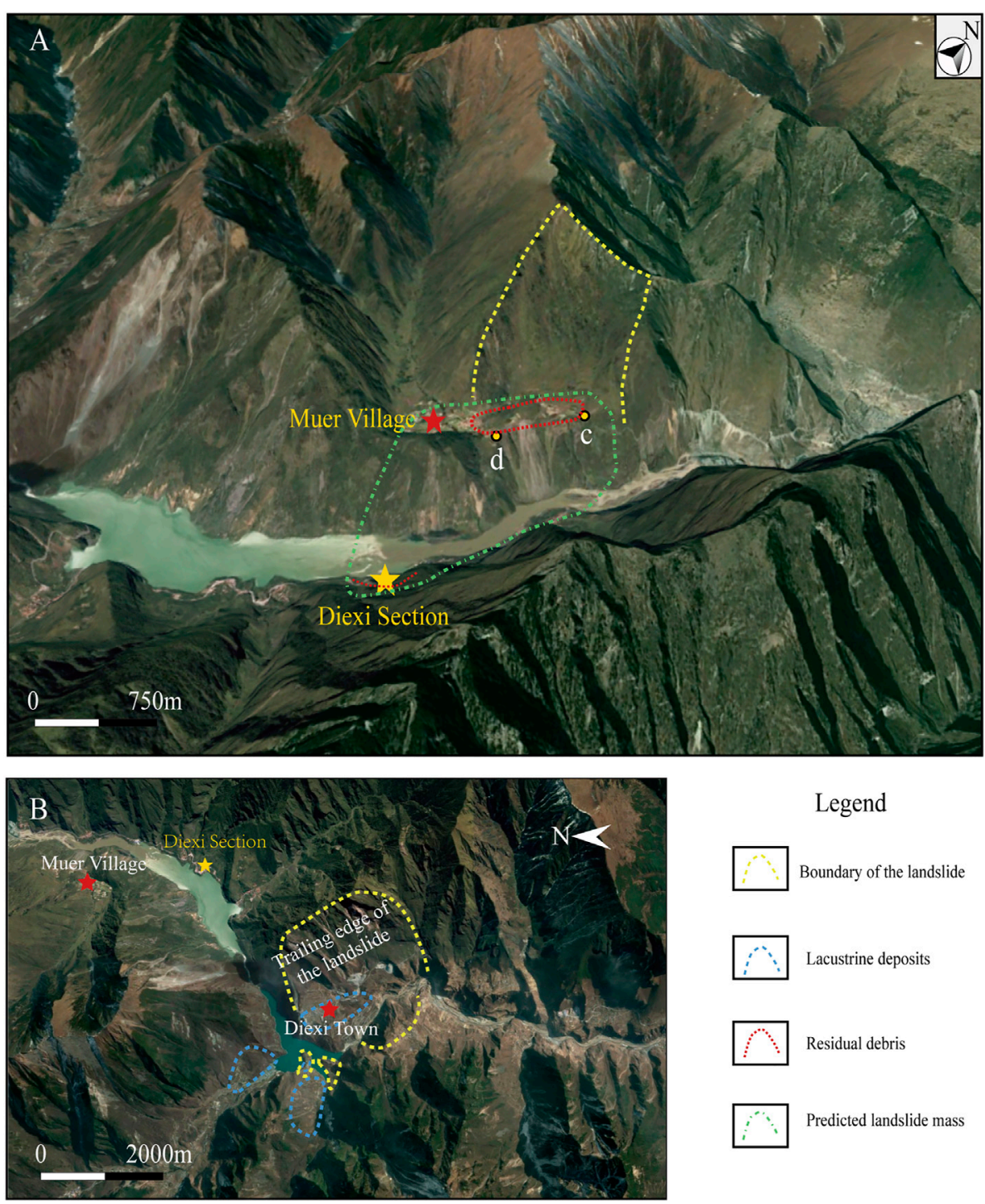

Legend
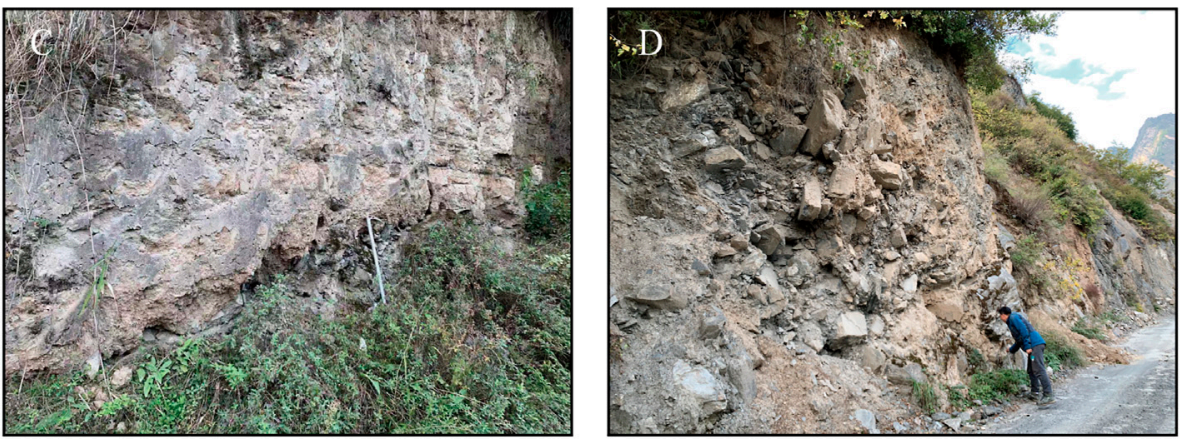

FIGURE 7 | (A) Muer landslide. The yellow dotted line represents the surface of the ancient landslide, the red dotted line represents the residual debris, and the light green dotted line represents the likely size of the landslide. (B) Jiaochang landslide (Ma et al., 2018). (C) and (D) Gravel layer and lacustrine layer located on the platform of Muer village. The base map was taken from Google Earth. 

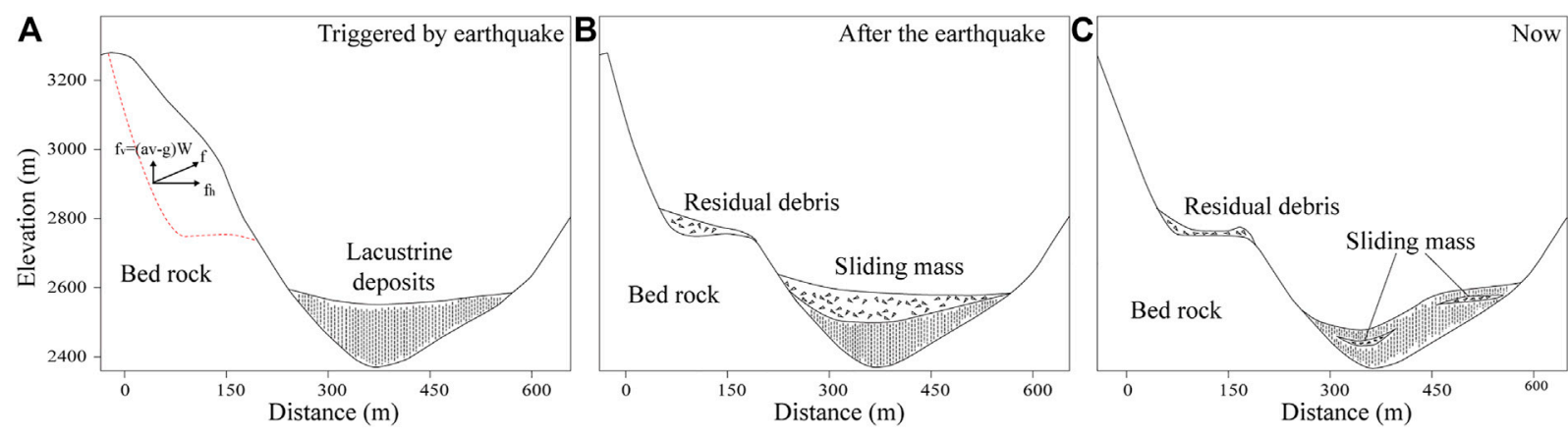

FIGURE 8 | (A) When an earthquake occurs, the surrounding mountains are affected by seismic waves, and rocks break and fall into the lake. (B) After the landslide occurs, the majority of the sliding rock mass accumulates in the lake, and a small amount of the debris remains on the platform. (C) After a long period of evolution, the landslide sediments are buried by lacustrine sediments.

suggesting that this area has since undergone a long period of recovery. The platform at Muer village is composed of a low-angle bedding plane and a steep joint surface, showing the characteristics of a typical terraced-shaped landslide (Figure 8C). Many such landslides were found in the upper reach of the Min River after the 2008 Wenchuan Earthquake (Yin et al., 2009; Zhang et al., 2011). Yin et al. (2009) proposed that during seismic shaking, the landslide (rock) mass detaches from underlying rock along the discontinuities by an external force, and the terraced shaped sliding surface is left in the site of the landslide.

Ma et al. (2018) found a barrier dam composed of boulder fragments with maximum sizes of $5-8 \mathrm{~m}$ near Diexi town (Figure 7B). The main body of the Diexi landslide dam is located near Jiaochang village and is approximately $3 \mathrm{~km}$ long and $1 \mathrm{~km}$ wide. The remaining dam sediments are mainly located on the eastern bank of the Min River, with a small amount of material on the western bank. The altitude of the main body of the barrier dam on the east bank is approximately $2,316 \mathrm{~m}$, and the residual landslide on the west bank is approximately $2,162 \mathrm{~m}$. The height difference between the two bodies is approximately $154 \mathrm{~m}$, and the horizontal distance between the residual body on the east bank and that on the west bank is approximately $1,000 \mathrm{~m}$. Similar to the landslide that likely triggered the Diexi gravel layer, the gravel sediments near Muer village are mainly located on the western bank of the river near the Minjiang fault, while a small amount of residue occurs in the lacustrine layer on the eastern bank. The altitude of the gravel layer in the Diexi section is approximately 2,308 $\mathrm{m}$, and the altitude of the boundary between the exposed gravel layer and lacustrine layer in Muer village is approximately $2,525 \mathrm{~m}$, with a height difference of approximately $217 \mathrm{~m}$. The distance between the exposed gravel layer in Muer village and the far end of the gravel layer is approximately $1,000 \mathrm{~m}$. Compared with the barrier dam at Diexi town, the height difference between the main and residual bodies is similar.

Using the geomorphic features on the east bank of the river and the remaining landslide bodies in the Diexi section on the west bank, we reconstruct this ancient landslide event (Figure 8). When the earthquake occurred, the landslide (rock) detached from the bedrock along the rupture. Due to the subsequent movement, most of the rock mass was displaced from the shallowly dipping bedding plane and over the edge of the steeply dipping joint surface before freefalling into the lake. When the landslide impacted the lacustrine sediments, the V-shaped lacustrine layer formed. As the boulder probably fell directly into the lake, there was no lateral erosion of the lacustrine layer. This movement is shown in the Diexi section, as the lacustrine layer is curved because of the impact but can be continuously traced across the outcrop. The remaining landslide gravel sediments were subsequently covered by lacustrine deposits within the barrier lake (Figure 8C).

\section{CONCLUSION}

The tectonic and climatic significance of the gravel layer is investigated in the Diexi lacustrine section on the eastern TP in this study. Based on the ages of three charcoal samples and two OSL samples, the gravel layer in the Diexi section is dated to approximately $16.79 \mathrm{ka}$ BP. Some evidences may indicate the origin of gravel layer: 1) The gravel layer is clast-supported with poorly rounded and unsorted clasts; 2) The underlying lacustrine sediments show a typical V-shaped curve but are not eroded; 3 ) An abrupt lithologic change is observed from the gravel layer to the overlying lacustrine sediments, with no gradual change in grain size or depositional bedding; 4) The SSDs underlying the gravel layer extends horizontally and can be traced along the entire section; 5) Based on the intensity attenuation model and the historical seismic records, if the gravel event was triggered by an earthquake, it could have had a magnitude of $M_{s}>7.3$, and this result is consistent with the frequent occurrence of large earthquakes in Diexi area 6) The platform as the source of the gravel layer at Muer village shows the characteristics of a typical terraced-shaped landslide. These features indicate that the gravel layer was most likely formed by a landslide triggered by an earthquake rather than heavy rain or flooding. The triggers and characteristics of the landslide are preliminarily reconstructed based on the geomorphic features near the Diexi section. The new findings in this study provide new insights into the reconstruction of paleoseismic sequence using gravel layers in the tectonically active regions. 


\section{DATA AVAILABILITY STATEMENT}

The original contributions presented in the study are included in the article/Supplementary Material, further inquiries can be directed to the corresponding author.

\section{AUTHOR CONTRIBUTIONS}

SZ: Conceptualization, Methodology, Validation, Formal analysis, Investigation, Data Curation, Writing-Original Draft, Writing-Review \&amp; Editing, Visualization. HJ: Methodology, Investigation, Resources, Writing-Review and Editing, Project administration, Funding acquisition. JF: Methodology, Investigation, Writing- Review and Editing. HX: Conceptualization, Methodology, Writing-Review and Editing. WS: Methodology, Investigation. QG: Methodology, Investigation. XW: Methodology, Investigation.

\section{REFERENCES}

Aitken, M. J. (1998). An Introduction to Optical Dating: The Dating of Quaternary Sediments by the Use of Photon-Stimulated Luminescence. Oxford: Oxford University Press.

Allen, T. I., Wald, D. J., and Worden, C. B. (2012). Intensity Attenuation for Active Crustal Regions. J. Seismol 16 (3), 409-433. doi:10.1007/s10950-012-9278-7

Arnold, L. J., and Roberts, R. G. (2009). Stochastic Modelling of Multi-Grain Equivalent Dose (De) Distributions: Implications for OSL Dating of Sediment Mixtures. Quat. Geochronol. 4, 204-230. doi:10.1016/j.quageo.2008.12.001

Bakun, W. H., and Wentworth, C. M. (1997). Estimating Earthquake Location and Magnitude from Seismic Intensity Data. Bull. Seismological Soc. America 87 (6), 1502-1521. doi:10.1016/S0009-2541(97)00104-6

Begin, Z. B., Steinberg, D. M., Ichinose, G. A., and Marco, S. (2005). A 40,000 Year Unchanging Seismic Regime in the Dead Sea Rift. Geol 33 (4), 257-260. doi:10.1130/G21115.1

Chandler, A. M., and Lam, N. T. K. (2002). Intensity Attenuation Relationship for the South China Region and Comparison with the Component Attenuation Model. J. Asian Earth Sci. 20 (7), 775-790. doi:10.1016/ S1367-9120(01)00054-2

Chen, H., Lin, G.-W., Lu, M.-H., Shih, T.-Y., Horng, M.-J., Wu, S.-J., et al. (2011). Effects of Topography, Lithology, Rainfall and Earthquake on Landslide and Sediment Discharge in Mountain Catchments of southeastern Taiwan. Geomorphology 133 (3-4), 132-142. doi:10.1016/j.geomorph.2010.12.031

Chen, K.-T., and Wu, J.-H. (2018). Simulating the Failure Process of the Xinmo Landslide Using Discontinuous Deformation Analysis. Eng. Geology. 239, 269-281. doi:10.1016/j.enggeo.2018.04.002

Chen, M., Tang, C., Xiong, J., Shi, Q. Y., Li, N., Gong, L. F., et al. (2020). The LongTerm Evolution of Landslide Activity Near the Epicentral Area of the 2008 Wenchuan Earthquake in China. Geomorphology 367, 107317. doi:10.1016/ j.geomorph.2020.107317

Chen, R., Chen, J., Ma, J., and Cui, Z. (2019). Quartz Grain Surface Microtextures of Dam-Break Flood Deposits from a Landslide-Dammed lake: A Case Study. Sediment. Geology. 383, 238-247. doi:10.1016/j.sedgeo.2019.02.010

Chen, S. F., Wilson, C. J. L., Deng, Q. D., Zhao, X. L., and Zhi, L. L. (1994). Active Faulting and Block Movement Associated with Large Earthquakes in the Min Shan and Longmen Mountains, Northeastern Tibetan Plateau. J. Geophys. Res. 99 (B12), 24025-24038. doi:10.1029/94JB02132

China Earthquake Adminstration (1999). Historical Strong Earthquake Catalog of China (2300 BC-1911 AD). Beijing: Earthquake Publishing House. (in Chinese).

Fan, J., Wei, X., Shi, W., Guo, Q., Zhang, S., Xu, H., et al. (2020). Response of Tree Rings to Earthquakes during the Past 350Â Years at Jiuzhaigou in the Eastern Tibet. Sci. Total Environ. 731, 138714. doi:10.1016/j.scitotenv.2020.138714

\section{FUNDING}

This work was supported by the National Key Research and Development Program of China (Project No. 2017YFC1501001-1 and No. 2017YFC1501000), the National Natural Science Foundation of China (41572346) and National Nonprofit Fundamental Research Grant of China, Institute of Geology, China Earthquake Administration (IGCEA1906).

\section{ACKNOWLEDGMENTS}

Special thanks go to the Beta Laboratory, University of California, Irvine, USA for AMS dating and the Luminescence Research Laboratory at Linyi University for OSL dating. The authors are also immensely grateful to the editor DW and the three reviewers for their valuable comments which significantly improved the quality and clarity of this manuscript.

Ferry, M., Meghraoui, M., Karaki, N. A., Al-Taj, M., and Khalil, L. (2011). Episodic Behavior of the Jordan Valley Section of the Dead Sea Fault Inferred from a 14Ka-Long Integrated Catalog of Large Earthquakes. Bull. Seismological Soc. America 101, 39-67. doi:10.1785/0120100097

Finkel, R. C., Owen, L. A., Barnard, P. L., and Caffee, M. W. (2003). Beryllium-10 Dating of Mount Everest Moraines Indicates a strong Monsoon Influence and Glacial Synchroneity throughout the Himalaya. Geol 31, 561-564. doi:10.1130/ 0091-7613(2003)031<0561:bdomem >2.0.co;2

Guan, Q. Y., Pan, B. T., Li, N., Zhang, J. D., and Xue, L. J. (2011). Timing and Significance of the Initiation of Present Day Deserts in the Northeastern Hexi Corridor, China. Palaeogeogr. Palaeoclimatol. Palaeoecol. 306(1-2), 70-74. doi:10.1016/j.palaeo.2011.03.029

Harris, C., Murton, J., and Davies, M. C. R. (2000). Soft-sediment Deformation during Thawing of Ice-Rich Frozen Soils: Results of Scaled Centrifuge Modelling Experiments. Sedimentology 47 (3), 687-700. doi:10.1046/j.13653091.2000.00322.x

Heyman, J., Stroeven, A. P., Caffee, M. W., Hättestrand, C., Harbor, J. M., Li, Y., et al. (2011). Palaeoglaciology of Bayan Har Shan, NE Tibetan Plateau: Exposure Ages Reveal a Missing LGM Expansion. Quat. Sci. Rev. 30(15-16), 1988-2001. doi:10.1016/j.quascirev.2011.05.002

Huang, R. Q., and Li, W. L. (2009). Analysis of the Geo-Hazards Triggered by the 12 May 2008 Wenchuan Earthquake, China. Bull. Eng. Geol. Environ. 68(3), 363-371. doi:10.1007/s10064-009-0207-0

Jiang, H., Mao, X., Xu, H., Yang, H., Ma, X., Zhong, N., et al. (2014). Provenance and Earthquake Signature of the Last Deglacial Xinmocun Lacustrine Sediments at Diexi, East Tibet. Geomorphology 204, 518-531. doi:10.1016/ j.geomorph.2013.08.032

Jiang, H., Zhong, N., Li, Y., Ma, X., Xu, H., Shi, W., et al. (2017). A Continuous 13.3-ka Record of Seismogenic Dust Events in Lacustrine Sediments in the Eastern Tibetan Plateau. Sci. Rep. 7(1), 15686. doi:10.1038/s41598-017$16027-8$

Jiang, H., Zhong, N., Li, Y., Xu, H., Yang, H., and Peng, X. (2016). Soft Sediment Deformation Structures in the Lixian Lacustrine Sediments, Eastern Tibetan Plateau and Implications for Postglacial Seismic Activity. Sediment. Geology. 344, 123-134. doi:10.1016/j.sedgeo.2016.06.011

Keefer, D. K. (1984). Landslides Caused by Earthquakes. Geol. Soc. America Bull. 95 (4), 406. doi:10.1130/0016-7606(1984)95<406:lcbe>2.0.co;2

Kong, P., Na, C., Fink, D., Zhao, X., and Xiao, W. (2009). Moraine Dam Related to Late Quaternary Glaciation in the Yulong Mountains, Southwest China, and Impacts on the Jinsha River. Quat. Sci. Rev. 28, 3224-3235. doi:10.1016/ j.quascirev.2009.08.005

Kong, P., Zheng, Y., and Fu, B. (2011). Cosmogenic Nuclide Burial Ages and Provenance of Late Cenozoic Deposits in the Sichuan Basin: Implications for Early Quaternary Glaciations in East Tibet. Quat. Geochronol. 6, 304-312. doi:10.1016/. .quageo.2011.03.006 
Kremer, K., Wirth, S. B., Reusch, A., Fäh, D., Bellwald, B., Anselmetti, F. S., et al. (2017). Lake-sediment Based Paleoseismology: Limitations and Perspectives from the Swiss Alps. Quat. Sci. Rev. 168, 1-18. doi:10.1016/ j.quascirev.2017.04.026

Lei, J. C., Gao, M. T., and Yu, Y. X. (2007). Seismic Motion Attenuation Relations in Sichuan and Adjacent Areas. Acta Seismologica Sinica 29 (5), 500-511. (In Chinese). doi:10.1007/s11589-007-0532-y

Li, B., Sun, D., Xu, W., Wang, F., Liang, B., Ma, Z., et al. (2017). Paleomagnetic Chronology and Paleoenvironmental Records from Drill Cores from the Hetao Basin and Their Implications for the Formation of the Hobq Desert and the Yellow River. Quat. Sci. Rev. 156, 69-89. doi:10.1016/ j.quascirev.2016.11.023

Li, G., West, A. J., Densmore, A. L., Jin, Z., Parker, R. N., and Hilton, R. G. (2014b). Seismic Mountain Building: Landslides Associated with the 2008 Wenchuan Earthquake in the Context of a Generalized Model for Earthquake Volume Balance. Geochem. Geophys. Geosyst. 15 (4), 833-844. doi:10.1002/ 2013GC005067

Li Jijun, J. J. (1991). The Environmental Effects of the Uplift of the Qinghai-Xizang Plateau. Quat. Sci. Rev. 10, 479-483. doi:10.1016/0277-3791(91)90041-R

Li, Y. H., Jiang, H. C., Xu, H. Y., and Liang, L. J. (2015). Analyses on the Triggering Facrors of Large Quantities of Landslides in the Upper Reaches of Minjiang River, Sichuan Province. Seismology Geology. 37 (4), 1147-1161. (In Chinese). doi:10.3975/cagsb.2019.102302

Li, Z., Sun, D., Chen, F., Wang, F., Zhang, Y., Guo, F., et al. (2014a). Chronology and Paleoenvironmental Records of a Drill Core in the central Tengger Desert of China. Quat. Sci. Rev. 85, 85-98. doi:10.1016/j.quascirev.2013.12.003

Liang, L., and Jiang, H. (2017). Geochemical Composition of the Last Deglacial Lacustrine Sediments in East Tibet and Implications for Provenance, Weathering, and Earthquake Events. Quat. Int. 430, 41-51. doi:10.1016/ j.quaint.2015.07.037

Liu, T. S., Ding, M. L., and Derbyshire, E. (1996). Gravel Deposits on the Margin of the Qinghai-Xizang Plateau and Their Environmental Significance. Palaeogeogr. Palaeoclimatol. Palaeoecol. 120, 159-170. doi:10.1016/00310182(95)00039-9

Lu, Y., Wetzler, N., Waldmann, N., Agnon, A., Biasi, G. P., and Marco, S. (2020). A 220,000-Year-Long Continuous Large Earthquake Record on a Slow-Slipping Plate Boundary. Sci. Adv. 6 (48), eaba4170. doi:10.1126/sciadv.aba4170

Ma, J., Chen, J., Cui, Z., Zhou, W., Liu, C., Guo, P., et al. (2018). Sedimentary Evidence of Outburst Deposits Induced by the Diexi Paleolandslide-Dammed lake of the Upper Minjiang River in China. Quat. Int. 464 (PT. B), 460-481. doi:10.1016/j.quaint.2017.09.022

Marco, S., Stein, M., Agnon, A., and Ron, h. (1996). Long-term Earthquake Clustering: A 50,000-year Paleoseismic Record in the Dead Sea Graben. J. Geophys. Res. 101, 6179-6191. doi:10.1029/95JB01587

Monecke, K., Anselmetti, F. S., Becker, A., Schnellmann, M., Sturm, M., and Giardini, D. (2006). Earthquake-induced Deformation Structures in lake Deposits: A Late Pleistocene to Holocene Paleoseismic Record for Central Switzerland. Eclogae Geol. Helv. 99 (3), 343-362. doi:10.1007/s00015-006-1193-x

Murray, A. S., and Wintle, A. G. (2000). Luminescence Dating of Quartz Using an Improved Single-Aliquot Regenerative-Dose Protocol. Radiat. Measurements 32, 57-73. doi:10.1016/S1350-4487(99)00253-X

Murray, A. S., and Wintle, A. G. (2003). The Single Aliquot Regenerative Dose Protocol: Potential for Improvements in Reliability. Radiat. Measurements 37, 377-381. doi:10.1016/S1350-4487(03)00053-2

Navratil, O., Evrard, O., Esteves, M., Legout, C., Ayrault, S., Némery, J., et al. (2012). Temporal Variability of Suspended Sediment Sources in an alpine Catchment Combining River/rainfall Monitoring and Sediment Fingerprinting. Earth Surf. Process. Landforms 37 (8), 828-846. doi:10.1002/esp.3201

Prescott, J. R., and Hutton, J. T. (1994). Cosmic ray Contributions to Dose Rates for Luminescence and ESR Dating: Large Depths and Long-Term Time Variations. Radiat. Measurements 23, 497-500. doi:10.1016/1350-4487(94)90086-8

Qiao, X. F., and Li, H. B. (2009). Effect of Earthquake and Ancient Earthquake on Sediments. J. Palaeogeogr. 11 (6), 593-610. (in Chinese). doi:10.7605/ gdlxb.2009.06.001

Reimer, P. J., Austin, W. E. N., Bard, E., Bayliss, A., Blackwell, P. G., Bronk Ramsey, C., et al. (2020). The IntCal20 Northern Hemisphere Radiocarbon Age Calibration Curve (0-55 Cal kBP). Radiocarbon 62 (4), 725-757. doi:10.1017/RDC.2020.41
Ren, J., Xu, X., Zhang, S., Yeats, R. S., Chen, J., Zhu, A., et al. (2018). Surface Rupture of the 1933 M 7.5 Diexi Earthquake in Eastern Tibet: Implications for Seismogenic Tectonics. Geophys. J. Int. 212 (3), 1627-1644. doi:10.1093/gji/ ggx498

Rodri'guez, C. E., Bommer, J. J., and Chandler, R. J. (1999). Earthquake-induced Landslides: 1980-1997. Soil Dyn. Earthquake Eng. 18 (5), 325-346. doi:10.1016/ s0267-7261(99)00012-3

Rodri'guez-Pascua, M. A., Calvo, J. P., Vicente, G. D., and Gómez-Gras, D. (2000). Soft-sediment Deformation Structures Interpreted as Seismites in Lacustrine Sediments of the Prebetic Zone, SE Spain, and Their Potential Use as Indicators of Earthquake Magnitudes during the Late Miocene. Sediment. Geology. 135 (14), 117-135. doi:10.1016/S0037-0738(00)00067-1

Rubin, D. M., Nelson, J. M., and Topping, D. J. (1998). Relation of Inversely Graded Deposits to Suspended-Sediment Grain-Size Evolution during the 1996 Flood experiment in Grand Canyon. Geol 26 (2), 99. doi:10.1130/0091-7613(1998) 026<0099:roigdt>2.3.co;2

Shi, W., Jiang, H. C., Mao, X., and Xu, H. Y. (2020). Pollen Record of Climate Change During the Last Deglaciation From the Eastern Tibeta Plateau. PLoS ONE 15 (5), e0232803. doi:10.1371/journal.pone.0232803

Si, J. T., and Liu, S. (2008). Geological Features, Deformation Sequence and Evolution of the Minjiang Fault on the Eastern Margin of the Qinghai-Tibet Plateau. Acta Geologica Sichuan 28 (1), 1-5. (in Chinese). doi:10.3969/ j.issn.1006-0995.2008.01.001

Sorensen, M. B., Stromeyer, D., and Grunthal, G. (2009). Attenuation of Macroseismic Intensity: A New Relation for the Marmara Sea Region, Northwest Turkey. Bull. Seismological Soc. America 99 (2A), 538-553. doi:10.1785/0120080299

Su, L.-j., Hu, K.-h., Zhang, W.-f., Wang, J., Lei, Y., Zhang, C.-l., et al. (2017). Characteristics and Triggering Mechanism of Xinmo Landslide on 24 June 2017 in Sichuan, China. J. Mt. Sci. 14 (9), 1689-1700. doi:10.1007/s11629017-4609-3

Sun, J. H. (2011). Study of Moderate-Strong Seismic Intensity Attenuation Relations in Sichuan-Yunan and its Adjacent Areas. Beijing: Institute of Earthquake Forecasting, CEA, 1-68. Master Dissertation (in Chinese).

Sun, J. (2005). Long-term Fluvial Archives in the Fen Wei Graben, central China, and Their Bearing on the Tectonic History of the India?Asia Collision System during the Quaternary. Quat. Sci. Rev. 24, 1279-1286. doi:10.1016/ j.quascirev.2004.08.018

Sun, X., Song, C., Wang, F., and Sun, M. (1997). Vegetation History of the Loess Plateau of China during the Last 100,000 Years Based on Pollen Data. Quat. Int. 37 (1), 25-36. (In Chinese). doi:10.1016/1040-6182(96)00008-0

Tang, C., Zhu, J., Ding, J., Cui, X. F., Chen, L., and Zhang, J. S. (2011). Catastrophic Debris Flows Triggered by a 14 August 2010 Rainfall at the Epicenter of the Wenchuan Earthquake. Landslides 8 (4), 485-497. doi:10.1007/s10346-0110269-5

Tang, R. C., Jiang, N. Q., and Liu, S. L. (1983). Recognition of the Geolgical Setting and the Seismogenic Condition for the Diexi Magnitude 7.5 Earthquake. J. Seismological Res. 6 (3), 327-338. (in Chinese)

Vandenberghe, J. (1992). Cryoturbations: a Sediment Structural Analysis. Permafrost Periglac. Process. 3 (4), 343-351. doi:10.1002/ppp.3430030408

Wang, F., Sun, D., Chen, F., Bloemendal, J., Guo, F., Li, Z., et al. (2015). Formation and Evolution of the Badain Jaran Desert, North China, as Revealed by a Drill Core from the Desert centre and by Geological Survey. Palaeogeogr. Palaeoclimatol. Palaeoecol. 426, 139-158. doi:10.1016/j.palaeo.2015.03.011

Wang, G., Li, T., Xing, X., and Zou, Y. (2014b). Research on Loess Flow-Slides Induced by Rainfall in July 2013 in Yan'an, NW China. Environ. Earth Sci. 73 (12), 7933-7944. doi:10.1007/s12665-014-3951-9

Wang, J., Gao, H. S., Pan, B. T., Du, G. Y., Li, Z. M., Cao, B., et al. (2010). Pleoflood Sediment of Shagou River and its Response to the Climate Change during Early Holocene. Scientia Geographica Sinica 30 (6), 943-949. (in Chinese).

Wang, L. S., Wang, X. Q., Xu, X. N., Cui, J., Sheng, J. H., and Zhang, Z. L. (2012). Significances of Studying the Diexi Paleo-Dammed lake at the Upstream of Minjiang River, Sichuan, China. Quat. Sci. 32 (5), 999-1010. (in Chinese). doi:10.3969/j.issn.1001-7410.2012.05.16

Wang, L. S., Wang, X. Q., Xu, X. N., and Cui, J. (2007). What Happened on the Upstream of Miniiang River in Sichuan Province 20000 Years Ago. Earth Sci. Front. 14 (4), 189-196. (in Chinese). doi:10.1016/s1872-5791(07) 60037-2 
Wang, P., Qiu, W. L., and Zhang, B. (2009). Origin of Deformational Structures of Soft Sediments in Moraines of the Zagunao Area, Western Sichuan. Quat. Sci. 29 (3), 484-493. (In Chinese). doi:10.1111/j.1749-6632.2008.04319.x

Wang, P., Zhang, B., Qiu, W., and Wang, J. (2011). Soft-sediment Deformation Structures from the Diexi Paleo-Dammed Lakes in the Upper Reaches of the Minjiang River, East Tibet. J. Asian Earth Sci. 40 (4), 865-872. doi:10.1016/ j.jseaes.2010.04.006

Wang, S. Y., Yu, Y. X., Gao, A. J., and Yan, X. J. (2000). Development of Attenuation Relations for Ground Motion in China. Eartgquake Res. China 16 (2), 99-106. (in Chinese). doi:10.3969/j.issn.1001-4683.2000.02.001

Wang, X. Q., Li, Y. R., Yuan, Y., Zhou, Z., and Wang, L. S. (2014a). Palaeoclimate and Palaeoseismic Events Discovered in Diexi Barrier lake on the Minjiang River, China. Nat. Hazards Earth Syst. Sci. 14 (8), 2069-2078. doi:10.5194/ nhess-14-2069-2014

Wang, X., Yang, Z., Løvlie, R., and Min, L. (2004). High-resolution Magnetic Stratigraphy of Fluvio-Lacustrine Succession in the Nihewan Basin, China. Quat. Sci. Rev. 23, 1187-1198. doi:10.1016/j.quascirev.2003.11.007

Wei, X. T., Jiang, H. C., Xu, H. Y., Fan, J. W., Shi, W., Guo, Q. Q., et al. (2021). Response of Sedimentary and Pollen records to the 1933 Diexi Earthquake on the Eastern Tibetan Plateau. Ecol. Ind., 129. doi:10.1016/j.ecolind.2021.107887

Wetzler, N., Marco, S., and Heifetz, E. (2010). Quantitative Analysis of Seismogenic Shear-Induced Turbulence in lake Sediments. Geology 38 (4), 303-306. doi:10.1130/G30685.1

Xiao, L., and Yu, Y. X. (2011). Earthquake Intensity Attenuation Relationship in Western China. Technology Earthquake Disaster Prev. 6 (4), 358-371. (in Chinese). doi:10.3969/j.issn.1673-5722.2011.04.002

Xu, C., Xu, X., Zhou, B., and Yu, G. (2013). Revisions of the M 8.0 Wenchuan Earthquake Seismic Intensity Map Based on Co-seismic Landslide Abundance. Nat. Hazards 69 (3), 1459-1476. doi:10.1007/s11069-013-0757-0

Xu, H., Chen, J., Cui, Z., and Chen, R. (2020). Sedimentary Facies and Depositional Processes of the Diexi Ancient Dammed Lake, Upper Minjiang River, China. Sediment. Geology. 398, 105583. doi:10.1016/j.sedgeo.2019.105583

Xu, H., Jiang, H., Liu, K.-b., and Zhong, N. (2020). Potential Pollen Evidence for the 1933 M 7.5 Diexi Earthquake and Implications for post-seismic Landscape Recovery. Environ. Res. Lett. 15, 094043. doi:10.1088/1748-9326/ab9af6

Xu, H., Jiang, H., Yu, S., Yang, H., and Chen, J. (2015). OSL and Pollen Concentrate 14C Dating of Dammed lake Sediments at Maoxian, East Tibet, and Implications for Two Historical Earthquakes in $\mathrm{AD} 638$ and 952. Quat. Int. 371, 290-299. doi:10.1016/j.quaint.2014.09.045

$\mathrm{Xu}$, L., and Zhou, S. (2014). Late Quaternary Fluvial Terraces Near the Daocheng Ice Cap, Eastern Tibetan Plateau. Quat. Res. 81, 452-463. doi:10.1016/ j.yqres.2013.08.007

Xu, X., Wen, X., Chen, G., and Yu, G. (2008). Discovery of the Longriba Fault Zone in Eastern Bayan Har Block, China and its Tectonic Implication. Sci. China Ser. D-earth Sci. 51 (9), 1209-1223. doi:10.1007/s11430-008-0097-1

Yin, Y., Wang, F., and Sun, P. (2009). Landslide Hazards Triggered by the 2008 Wenchuan Earthquake, Sichuan, China. Landslides 6 (2), 139-152. doi:10.1007/ s10346-009-0148-5

Zhang, M., Yin, Y., Wu, S., Zhang, Y., and Han, J. (2011). Dynamics of the Niumiangou Creek Rock Avalanche Triggered by 2008 Ms 8.0 Wenchuan Earthquake, Sichuan, China. Landslides 8 (3), 363-371. doi:10.1007/s10346-011-0265-9

Zhang, P. Z., Deng, Q. D., Zhang, G. M., Ma, J., Gan, W. J., Min, W., et al. (2003). Active Tectonic Blocks and strong Earthquakes in continental China. Sci. China (Series D). 46 (Suppl. 1), 13-24. doi:10.1360/03dz000210.1360/03yf9003
Zhang, P. Z. (2008). Tectonic Deformation, Strain Partitioning, and Crustal Dynamics of the Western Sichuan Region. Sci. China (Series D). 38, 1041-1056. (In Chinese). doi:10.1360/zd2008-38-9-1041

Zhang, S., Li, R., Wang, F., and Iio, A. (2019). Characteristics of Landslides Triggered by the 2018 Hokkaido Eastern Iburi Earthquake, Northern Japan. Landslides 16 (9), 1691-1708. Published online. doi:10.1007/s10346-01901207-6

Zhao, S., Chigira, M., and Wu, X. (2019). Gigantic Rockslides Induced by Fluvial Incision in the Diexi Area along the Eastern Margin of the Tibetan Plateau. Geomorphology 338, 27-42. doi:10.1016/j.geomorph.2019.04.008

Zhong, N. (2018). Earthquake and Provenance Analysis of the Lacustrine Sediments in the Upper Reaches of the Min River during the Late Pleistocene. Prog. Earthquake Sci. 3, 46-48. doi:10.3969/j.issn.02534975.2018.03.010

Zhong, N., Jiang, H, C., Li, H. B., Xu, H. Y., Shi, W., Zhang, S. Q., et al. (2019). Last Deglacial Soft-Sediment Deformation at Shawan on the Eastern Tibetan Plateau and Implications for Deformation Processes and Seismic Magnitudes. Acta Geologica Sinica (English Edition) 93 (02), 430-450. doi:10.1111/17556724.13773

Zhong, N., Jiang, H. C., Li, H. B., Xu, H. Y., and Huang, X. L. (2020b). The Genetic Types of Soft Sediment Deformation Structures and Their Characteristics in the Fluvial-Lacustrine Sediments, Eastern Tibetan Plateau. Acta Geoscientica Sinica 41 (1), 23-36. (in Chinese). doi:10.3975/cagsb.2019.102302

Zhong, N., Li, H., Jiang, H., Lu, H., Zheng, Y., Han, S., et al. (2020a). Typical SoftSediment Deformation Structures Induced by Freeze/Thaw Cycles: A Case Study of Quaternary Alluvial Deposits in the Northern Qiangtang Basin, Tibetan Plateau. Acta Geologica Sinica - English Edition 94 (1), 176-188. doi:10.1111/1755-6724.14345

Zhou, B. G., and Zhang, Y. M. (1994). Some Characteristics of Earthquake-Induced Landslide in Southwestern China. Northwest. Seismological J. 16 (1), 95-103. (in Chinese). CNKI:SUN:ZBDZ.0.1994-01-016

Zhou, J.-w., Xu, F.-g., Yang, X.-g., Yang, Y.-c., and Lu, P.-y. (2016). Comprehensive Analyses of the Initiation and Landslide-Generated Wave Processes of the 24 June 2015 Hongyanzi Landslide at the Three Gorges Reservoir, China. Landslides 13 (3), 589-601. doi:10.1007/s10346-016-0704-8

Conflict of Interest: The authors declare that the research was conducted in the absence of any commercial or financial relationships that could be construed as a potential conflict of interest.

Publisher's Note: All claims expressed in this article are solely those of the authors and do not necessarily represent those of their affiliated organizations, or those of the publisher, the editors and the reviewers. Any product that may be evaluated in this article, or claim that may be made by its manufacturer, is not guaranteed or endorsed by the publisher.

Copyright (C) 2021 Zhang, Jiang, Fan, Xu, Shi, Guo and Wei. This is an open-access article distributed under the terms of the Creative Commons Attribution License (CC $B Y)$. The use, distribution or reproduction in other forums is permitted, provided the original author(s) and the copyright owner(s) are credited and that the original publication in this journal is cited, in accordance with accepted academic practice. No use, distribution or reproduction is permitted which does not comply with these terms. 